\title{
Opportunities for transnational and translational research in Europe
}

Opportunities for transnational and translational $R \& D$ was the title of a paper for this Journal's readers in 2005 (when it was still South African Psychiatry Review). It was intended to encourage exploring opportunities for collaborative research. ${ }^{1}$ So what has evolved? Here are some examples of what has been accomplished, and what is in the pipeline of psychiatric collaboration between South Africa (SA), Uganda, and Europe. My intention was not to approach this a a neo-colonialist, rather to stress what I believe to be mutually beneficial projects, emanating from the needs of the African psychiatric patient in various settings.

To move forward from the consequences of the academic boycott during the apartheid years, new friendships needed to be established. I gave my first talk in South Africa at Weskoppies Psychiatric Hospital in Pretoria in 1995, continuing to the academic centers of Cape Town, Bloemfontein, Johannesburg, and Durban. Tuviah Zabow reciprocated by coming to the Swedish Society of Medicine in 1997 to talk on Apartheid and Psychiatry. He was followed by Christopher Szabo in 2002 who lectured on Race and Psychiatric Services in Post-Apartheid South Africa. Subsequently Tuviah Zabow invited me to be a visiting lecturer at the University of Cape Town (UCT). In 2005, with a collaborative grant from the National Research Foundation (NRF) in South Africa and the Swedish Science Council shared with Dan Stein, I was given the opportunity to build relations with the Western Cape psychiatric community. Potential areas of collaboration were identified. Papers were jointly published on genetic studies in anxiety disorders. In the same year, Stephanie Burrows from South Africa presented a thesis at the Karolinska Institutet in Stockholm on Suicide Mortality in the South African Context. An exchange of undergraduate medical and nursing students was initiated between Uppsala University, Ersta Sköndal University College and UCT.

In 2006, the UCT Research Ethics Committee approved of a study by Swedish medical students of neuropsychiatric manifestations of HIV/AIDS in mine workers at the then Rand Mutual Hospital. ${ }^{2}$ When I presented on this topic at a European meeting in $2010^{3}$, there was a roaring silence, as many became aware of the clinical challenges that SA psychiatrists deal with on a daily basis. HIV-associated neurocognitive disorders are now a prioritized area for collaboration in the 5-year partnership agreement for double doctoral degrees signed in August 2012 between Karolinska Institutet, Makerere University and Stellenbosch

Correspondence

Prof C Allgulander

email: Christer.Allgulander@ki.se
University. Such a collaboration encompasses the following:

1. A holder of the double PhD degree will have the full recognition of the two universities and will become a future research fellow that can sustain and develop contacts between the two universities.

2. Research shall be carried out under the supervision and responsibility of two supervisors, one appointed by each partner Institution. Both supervisors will tutor the PhD student.

Beyond child and adolescent psychiatry at Stellenbosch University, we hope to also include the University of Witwatersrand's Division of Psychiatry through the Luthando HIV and Neuropsychiatry Unit at Chris Hani Baragwanath Academic Hospital, as well as the UCT's Neuropsychiatric Division. A joint symposium was held with collaboration in mind at the Biological Psychiatry Congress in Stellenbosch in 2011 on neuropsychiatric manifestations of HIV/AIDS.

Soraya Seedat represents SA psychiatry in introducing this topic in the newly established agreement between Stellenbosch University and Karolinska Institutet. This agreement is building on a similar collaboration with Makerere University in Uganda that has already yielded several dissertations. These doctoral students at Makerere University were tutored chiefly by Seggane Musisi, Hans Ågren, Peter Allebeck, and Solvig Ekblad.

Funding is essential, but how does one access such funding? The Erasmus Mundus program 2009-2013 funds master courses (Euro 24 000) and joint doctorates (Euro 60-130000 for a 3-year period) (http://eacea.ec.europa. eu/index en.php). A Stellenbosch student of psychiatric genetics has been awarded such a grant for studies at Karolinska Institutet.

Moving from Sweden to Europe, there is a program closing in 2013 to enable UCT researchers to spend a total of 138 months at European research centers or vice versa, namely the Joint European and South African Research Network in Anxiety Disorders (EUSARNAD). A grant of Euro 290000 is managed by David Baldwin at the University of Southampton in the UK and by Dan Stein at UCT. ${ }^{4}$ Five or more SA researchers have now benefited from this program in visiting Leiden University, University of Tartu, University of Hertfordshire/University of Cambridge, the University of Göttingen, and the University of Southampton. These projects have dealt with social anxiety and depression in alcohol use disorders, cognitive and emotional dysfunction in Cushing's syndrome, proteomics in the biobank of a prospective cohort, MRI findings in alcohol use disorder with and without anxiety, 
and neurocognitive function in $\mathrm{OCD}$ patients.

Future researchers looking for grants can monitor Horizon 2020, the umbrella name for research coordination and funding by the European Union. The program is expected to be budgeted and launched in January 2014 (http://ec.europa.eu/research/horizon2020/index en.cfm? pg=home\&video=none). This source is something to look out for to fund collaborative research that has great promise to be mutually beneficial.

In conclusion, several psychiatric research collaborations have been established since the academic boycott during the apartheid years. This came about because of efforts by European as well as African psychiatrists in both SA and Uganda. In addition, there have been numerous presentations by distinguished SA psychiatrists at international meetings that I have not mentioned in this commentary, book editions, electives for undergraduate nursing and medical students, and personal transnational friendships. Pharmaceutical drug development has built on multicenter studies of both SA and European centers. Within the African context South Africa is now part of the international community of academic psychiatric research for the benefit of all parties.

C Allgulander Karolinska Institutet, Department of Clinical Neuroscience, Stockholm, Sweden

\section{References}

1. Allgulander C. Opportunities for transnational and translational R\&D. S Afr Psychiatry Rev 2005;1 9:1 13-14.

2. Säll L, Salamon E, Allgulander C, Owe-Larsson B. Psychiatric symptoms and disorders in HIV infected mine workers in South Africa.A retrospective descriptive study of first admissions. Afr J Psychiatry 2009;12(3):206-12.

3. Allgulander C. Pharmacotherapy of neuropsychiatric manifestations of HIVIAIDS. 11 th meeting, International Mood and Anxiety Disorders, Vienna, November 2010.

4. Baldwin DS, Stein DJ. A joint European and South African research network in anxiety disorders. Human Psychopharmacol 2012;27(1):4-5

\section{Erratum: Dementia masquerading as mania - when should it be suspected?}

It should be noted that the above mentioned scientific letter "Dementia masquerading as mania - when should it be suspected?" published in the January 2013 edition of the Journal was solely attributed to R Shah. Authorship should have included SK Mattoo and K Kodakandla. All authors are from the Department of Psychiatry, Post-Graduate Institute of Medical Education and Research, Chandigarh, India.

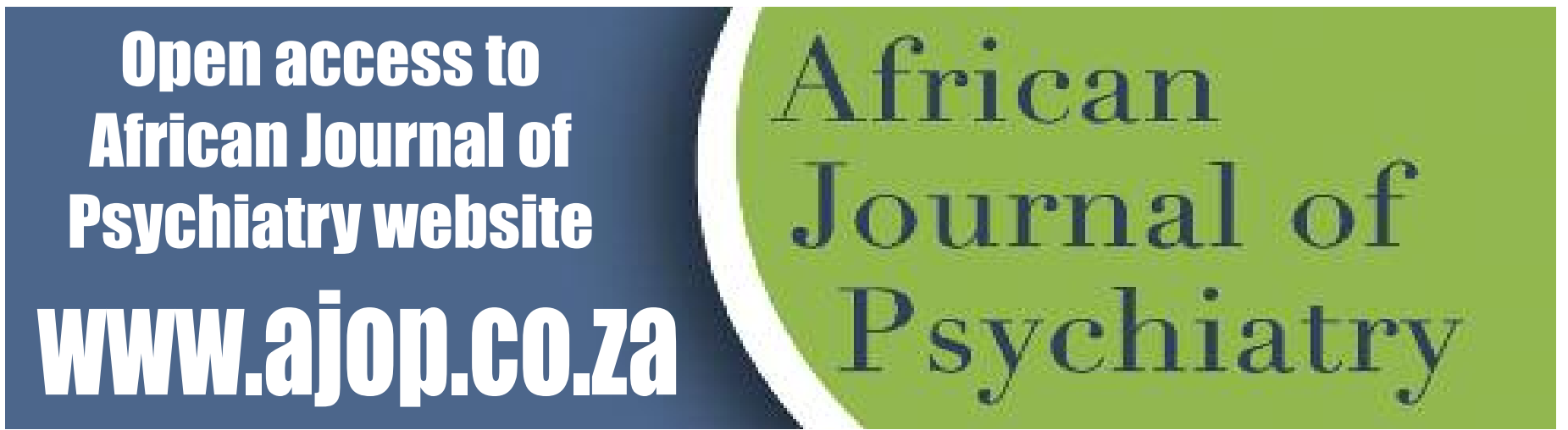

